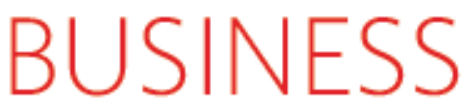

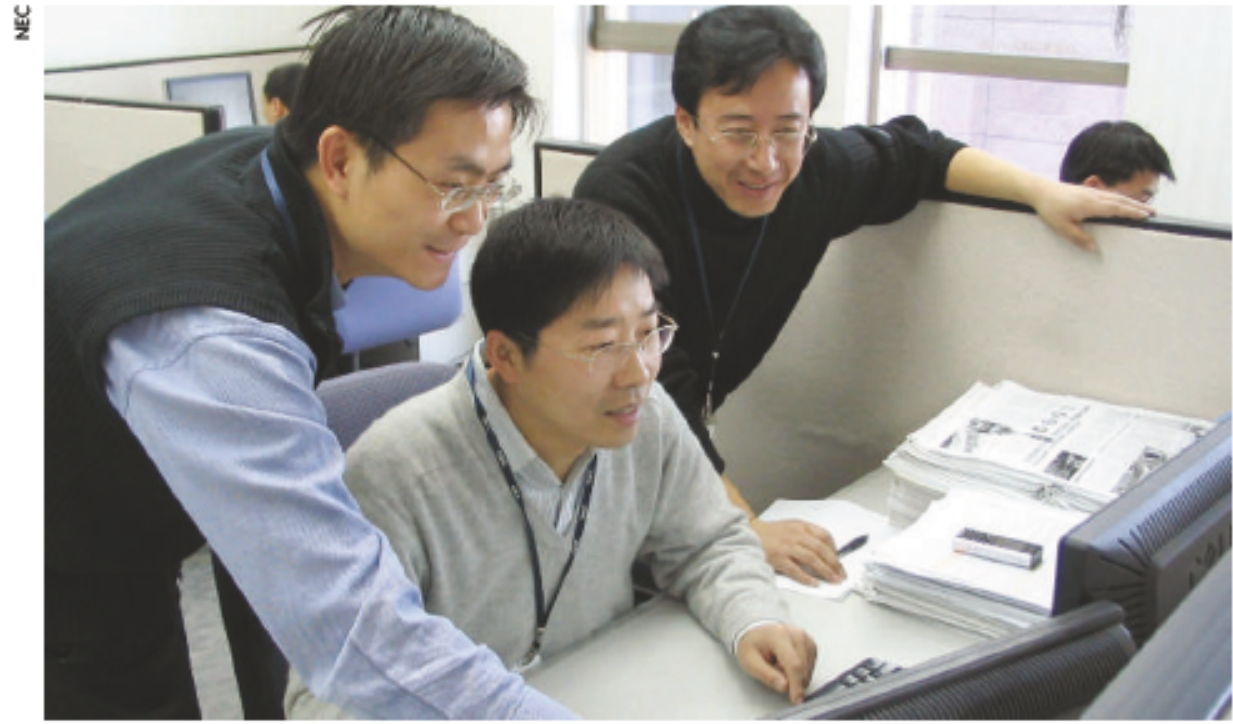

\section{Across China's frontier}

\section{China has become the preferred place for international firms to open research labs - and Japan is leading the way, reports Ichiko Fuyuno.}

$$
\text { - }
$$
lectronics engineer Min-Yu Hsueh wasn't planning to swap California for Beijing, but when the invite came he found it very hard to refuse. AChinese-American entrepreneur based in San Jose, Hsueh was three years ago working on setting up his next company. Then, out of the blue, Japanese electronics giant NEC offered him the chance to run its first research lab in China.

${ }^{\alpha}$ They said: 'China is expanding its market, so we want to play there more efficiently, and we need to invent new technologies,', Hsueh recalls. He was impressed by the plans, and now runs NEC Laboratories China in Beijing, leading a team of 40 researchers, most of them computer scientists.

NEC is just one of a host of Japanese companies to have set up research facilities in China in recent years. These firms hope to hire China's well-trained and relatively inexpensive young scientists, and to adapt existing products to the burgeoning Chinese market. The companies

3 are encouraged by generous tax relief for invest-

ing in research and development, and hopes

8 that they will be able to secure intellectual property in China (see Nature 438, 420-421; 2005).

But for research managers brought up in Japan's system of teamwork and corporate loyalty, the fast-moving, Mandarin-speaking environment takes some getting used to. "It's challenging for them," says Hironori Uchibori, senior economist at Mizuho Research Institute in Tokyo. "But the importance of China is rising, so they are trying to make it work."

In 2005, Mizuho surveyed almost 1,400 medium and large industrial firms in Japan and found that more than 250 had already established research labs in China. Only 116 had done so in the United States.

Japanese firms are not the only ones heading for China. US electronics company Motorola was the first foreign firm to set up a research lab there, back in 1993. Since then there's been a veritable gold rush, and there are now some 700 labs operated by multinational companies, according to a 2005 United Nations report. That report found that firms favoured China more than any other nation as the location for expanding research and development over the next five years (see graph). In the survey, $60 \%$ of European companies said that they had plans to expand their research abroad, but fully $90 \%$ of Japanese ones said so.

Competition to hire top graduates is stiff in

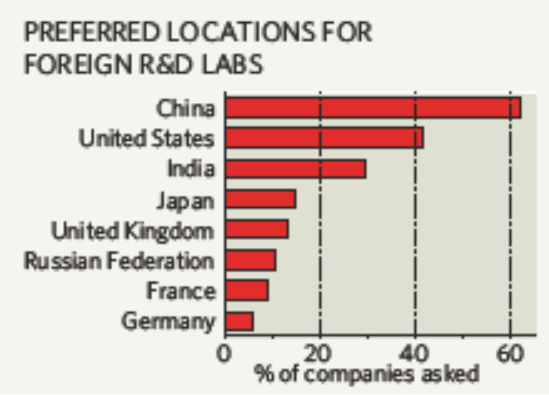

Cultural shift: NEC is encouraging a Western style of management at its Chinese laboratory.

China, and many Japanese companies are strengthening their ties with universities in a bid to snag students after they graduate. For example, Osaka-based Matsushita Electric Industrial Company has researchers that teach classes at Dalian University of Technology in the northeastern province of Liaoning. The company, best known for its Panasonic brand, has several labs in China and opened a software development facility in Dalian in 2004.

"It's tough to recruit good students there, so we want them to get interested in us," says Atsushi Ando of Matsushita's research strategy group. Matsushita says that over the next few years it will triple or quadruple the number of researchers and engineers at its Dalian lab from the current 100 .

But recruitment isn't the only issue: many Japanese firms are keen to train the Chinese students in their corporate ethos so that their recruits stay put. Hitachi and Fujitsu both say that they are trying to imbue young researchers with Japanese virtues, such as teamwork and corporate loyalty. Since Hitachi established a Chinese lab in 2000, it has invited many of its 60 Chinese researchers to Japan for six months to learn these virtues. "We started from scratch, so educating researchers was the toughest thing for our first five years," says Michiharu Nakamura, a Hitachi vice-president in charge of the Beijing laboratory.

Lab managers may laud the quality of Chinese graduates, but the monthly salaries paid the recruits are only about a quarter of the US $\$ 2,000$ or so that similar graduates get in Japan. And managers are aware that US companies such as Microsoft and IBM have a more positive image among students. Many Japanese employers also acknowledge that the research 'culture' in China, with its strong emphasis on individualism and competition, has more in common with that of the United States than with the Japanese model.

This might explain why NEC has let Hsueh take a Western approach to running his lab. His management practices are more Californian than Japanese: English is the working language, and researchers get financial bonuses for filing patents, publishing papers and producing ideas that become incorporated into prototypes. "This approach is a first for NEC, ${ }^{n}$ Hsueh says.

Other companies are also shifting responsibility from Japanese managers to Chinese nationals. Many group leaders at Hitachi, for example, are now Chinese. The main challenge over the next few years, Nakamura says, is to develop products there not just for China, but for global markets as well. 